\title{
Le culturalisme traditionaliste africaniste
}

Analyse d'une idéologie scientifique

Africanist Traditionalist Culturalism. Analysis of a Scientific Ideology

Jean-Pierre Olivier de Sardan

\section{OpenEdition}

\section{Journals}

Édition électronique

URL : https://journals.openedition.org/etudesafricaines/16181

DOI : 10.4000/etudesafricaines.16181

ISSN : 1777-5353

Éditeur

Éditions de l'EHESS

Édition imprimée

Date de publication : 20 novembre 2010

Pagination : 419-453

ISBN : 978-2-7132-2252-8

ISSN : 0008-0055

Référence électronique

Jean-Pierre Olivier de Sardan, « Le culturalisme traditionaliste africaniste », Cahiers d'études africaines [En ligne], 198-199-200 | 2010, mis en ligne le 02 janvier 2013, consulté le 21 avril 2022. URL : http:// journals.openedition.org/etudesafricaines/16181; DOI : https://doi.org/10.4000/etudesafricaines. 16181

Ce document a été généré automatiquement le 21 avril 2022

(c) Cahiers d'Études africaines 


\title{
Le culturalisme traditionaliste africaniste
}

\author{
Analyse d'une idéologie scientifique \\ Africanist Traditionalist Culturalism. Analysis of a Scientific Ideology
}

Jean-Pierre Olivier de Sardan

1 Le comportement des agents publics en Afrique s'éloigne bien souvent des normes officielles. Certes, partout dans le monde, on constate l'existence d'écarts entre les prescriptions et les pratiques, entre ce que sont censés faire les fonctionnaires, et ce qu'ils font réellement. Mais l'écart est particulièrement prononcé dans les fonctions publiques africaines. On peut le dire autrement : en Afrique, plus qu'ailleurs, l'État réel est très éloigné de l'État formel. L'accord est assez général sur ce constat. Mais comment l'interpréter, comment l'expliquer ?'1.

2 C'est ici qu'intervient le concept de " culture ", qui est souvent invoqué, tant par le sens commun que par des chercheurs en sciences sociales, pour rendre compte de ce qui serait une "spécificité africaine ». Dans une telle perspective, l'État en Afrique serait d'abord un État à l'africaine, autrement dit un État immergé dans une culture africaine bien éloignée des normes occidentales de l'État. L'écart aurait pour cause le placage de règles occidentales (légales-rationnelles) organisant le fonctionnement officiel de l'État sur des sociétés africaines définies par des règles informelles tout autres, qui suivraient des lignes de pente culturelles fort différentes de celles qui, en Occident, sous-tendent la construction de l'État. Si les comportements des agents de l'État en Afrique sont si peu conformes aux normes officielles, ce serait au fond parce qu'ils suivraient des normes sociales issues pour une bonne part de leur culture ancestrale...

3 Cette position culturaliste érudite, largement répandue, qui est assumée et argumentée de façon très variable, n'est pas nouvelle (on en retrouve de très nombreuses traces dans les archives coloniales), mais elle est régulièrement réaffirmée, sous des habillages théoriques divers, et a connu un renouveau récent en science politique. Par exemple, Chabal et Daloz (1998) en ont développé une variante, avec un certain succès, en particulier en milieu anglophone, mais aussi en suscitant de nombreuses réactions 
critiques, face auxquelles ils ont tenu à réaffirmer plus théoriquement leur position dans un second ouvrage au titre significatif : Culture Troubles! (Chabal \& Daloz 2006).

Il y a en effet débat, au moins indirect et parfois direct, chez les politologues, autour de la posture culturaliste, qui a ici ou là été vigoureusement attaquée, en particulier par Jean-François Bayart (1996) dans un livre au titre lui aussi éloquent L'illusion identitaire.

5 Nous nous appuierons dans un premier temps sur ce débat pour décrire à quel point la notion de "culture africaine" est un haut lieu de projection de clichés et de stéréotypes, sans ancrage empirique, qui prennent la forme d'une idéologie scientifique qu'on pourrait appeler le "culturalisme traditionaliste africaniste» (стА). Ceci nous conduira à réexaminer l'histoire même du concept de "culture" dans le champ spécifique de l'anthropologie et de la sociologie, où l'on trouvera trace de tensions analogues récurrentes. La réorganisation sémantique de ce concept par Talcott Parsons et Clifford Geertz a ainsi pavé la voie à l'idéologie culturaliste, en décrochant le concept de ses ancrages empiriques. Enfin, nous tenterons de définir les conditions d'un usage alternatif mesuré, empiriquement fondé, du concept de "culture ", aussi éloigné que possible du culturalisme.

\section{Culture africaine et services publics : le débat}

6 Le culturalisme peut, à propos de l'Afrique, prendre des formes multiples : au-delà d'un fonds commun, qui affirme l'existence d'« une » culture africaine enracinée dans le passé et relevant de "valeurs " spécifiques, et qui insiste sur son rôle central dans le présent, on trouve d'innombrables variations. Les uns font l'apologie de ce que d'autres dénoncent. Le registre littéraire se distingue fortement du registre politique. Le monde des médias mobilise à longueur de journée des stéréotypes que le monde scientifique justifie ou récuse, selon les auteurs.

7 Les arguments culturalistes chez les responsables politiques africains sont fréquents et anciens : on pense par exemple aux théories de l'«authenticité » des années 1960, promues en particulier par Mobutu au Zaïre et Tombalbaye au Tchad, qui reviennent régulièrement à la surface, sous des formes certes moins excessives. Mais on pourrait aussi évoquer des rhétoriques plus intellectuelles et élaborées, comme les références à la charte médiévale du Mandé dite de Kurukan Fuga, proposée parfois comme modèle politique pour l'Afrique contemporaine ${ }^{2}$. Les traditions, les cultures nationales, la culture africaine, les savoirs endogènes sont régulièrement mobilisés dans les rhétoriques publiques par des entrepreneurs politico-identitaires. Par ailleurs, face à ce culturalisme militant "positif» (qui promeut le retour aux «valeurs africaines » comme solution) se dresse un culturalisme essayiste "négatif» (qui dénonce la prégnance des « valeurs africaines » comme problème) : l'ouvrage très contesté et très contestable du journaliste Stephen Smith (2003) Négrologie en est l'illustration. L'afropessimisme n'est qu'un culturalisme inversé qui impute aux « mentalités africaines » le « refus du développement» (Kabou 1991). Le culturalisme traditionaliste africaniste apparaît donc, pour ceux qui croient en la réalité de ses clichés, soit comme la source possible d'un développement enfin réussi ou d'une politique alternative, soit comme une malédiction qui enferme l'Afrique dans son passé et bloque tout changement. Il débouche, en termes normatifs, sur une extrême ambivalence, ce qui est un trait typique des idéologies : il est loué par les uns, honni par les autres, mais sur la base de clichés identiques. Il est frappant de voir que les hérauts d'un retour à la tradition 
africaine comme les contempteurs de sa permanence se retrouvent d'accord sur la nécessaire réhabilitation du phénomène ethnique : «Aux yeux de Smith enfin [...] "le tribalisme et l'ethnicité [...] sont les signes sous lesquels le continent naît à la modernité et ses élites à la démocratie", qu'il serait temps de rendre légitime " (Courade $2006: 25$ ).

Mais nous ne nous intéresserons ici ni au culturalisme populaire, ni au culturalisme littéraire, ni au culturalisme politique. Seul nous concernera le culturalisme savant, issu des milieux de la recherche, lorsqu'il s'exprime de façon argumentée, érudite, théorique, sur la question de la spécificité des États et de l'action publique en Afrique.

\section{Le CTA}

9 Les postulats de base de ce culturalisme savant sont relativement simples. Le faible respect en Afrique des règles du jeu formelles serait dû au poids des pratiques informelles, d'origines sociale et culturelle, qui s'inviteraient en permanence dans les dispositifs étatiques. La pression « communautaire », les coutumes locales, les valeurs traditionnelles, les représentations magico-religieuses, les habitudes clientélistes et patrimonialistes, les solidarités primordiales, les identités ethniques sont ainsi régulièrement invoquées. Seule une analyse de la culture africaine, et de son ancrage dans le passé, pourrait permettre de comprendre les pratiques politiques en vigueur.

Le recours au passé est en effet au cœur de l'argumentation, même si divers changements et adaptations sont bien sûr concédés à la culture traditionnelle en ses manifestations contemporaines. Car c'est le passé qui fournirait le socle du répertoire moral et symbolique des représentations des dirigeants et fonctionnaires africains aujourd'hui, c'est dans le passé que s'ancreraient les systèmes de sens et les structures de référence qui seraient au principe des pratiques politiques africaines: "This precolonial past provided the foundation for ideas about power, accountability, morality and society that remain terrifically powerful in Africa today " (Kelsall $2008: 633$ ). "The key features of the social grain in Africa today flow from a tradition, rooted in an economy, that is thousands of years old » (ibid. : 629).

11 C'est cette référence omniprésente, sur un mode latent ou explicite, à la tradition africaine qui est la marque spécifique du culturalisme africaniste. D'où notre expression de «culturalisme traditionaliste africaniste », СTA. Car, en effet, le concept de «culture » est en soi particulièrement polysémique, et peut évidemment avoir des acceptions non traditionalistes et circonscrites (on y reviendra) et par exemple s'appliquer à des représentations et des comportements partagés sans référence particulière à un passé lointain. En outre, des usages raisonnés du concept de culture peuvent permettre d'éviter de verser dans une idéologie culturaliste. En revanche, lorsqu'il est question d'Afrique, la posture culturaliste est toujours plus ou moins traditionaliste, quelles que soient les précautions rhétoriques parfois formulées ${ }^{3}$ ou les habits sémiologiques dont elle se revêt. Elle implique la présence presque obsédante du passé dans le présent. Ce passé reste cependant, il faut le souligner, toujours vague dans les argumentaires du CTA, il n'est nullement historiquement spécifié et analysé, on ne sait de lui que son caractère précolonial et sa rémanence. Loin d'une "histoire des mentalités ", qui appliquerait à l'Afrique la solide méthodologie historique qui a fait le succès de cette école en Europe, le passé culturel de l'Afrique n'est jamais historicisé par les culturalistes. C'est un passé sans histoire, un passé indéterminé, un passé sans 
périodisation, « un passé essentialisé ». C'est là un autre de ces signes qui ne trompent pas par lesquels se reconnaît une idéologie, fut-elle scientifique.

Bien évidemment, il ne saurait être question de récuser toute influence du passé sur le présent, bien au contraire! L'histoire est une dimension incontournable du présent. Mais c'est bien pour cela qu'elle doit être analysée sérieusement, minutieusement. Les passés incorporés dans les comportements d'aujourd'hui sont multiples, et exigent d'être situés, détaillés, argumentés. Par exemple, s'il s'agit de comprendre le fonctionnement assez particulier des bureaucraties africaines au Xxi siècle, c'est plutôt au Xx ${ }^{e}$ qu'au XIXe siècle qu'il faudrait remonter, avec l'instauration de l'État colonial, ou les modalités de passage à l'État postcolonial. En revanche, les rituels initiatiques sur la base des classes d'âge sont clairement d'origine précoloniale: mais qu'en reste-t-il véritablement aujourd'hui ? Sur la question de l'influence du passé, il faut être précis et rigoureux. Le СТА ne l'est pas, qui préfère procéder par généralités, et renvoyer à une traditionalité africaine vague et confuse, en minimisant systématiquement le poids et les effets de la période coloniale, pourtant décisive dans la perspective de la construction de l'État. Celle-ci n'aurait été qu'une parenthèse formelle, aux effets superficiels $s^{4}$. Une analyse du mode de gouvernance colonial (très éloigné des normes et valeurs des bureaucraties européennes de l'époque) montre au contraire que les administrations africaines contemporaines ont intériorisé, repris et développé nombre de ses caractéristiques: mépris de l'usager, recours aux intermédiaires, quête de privilèges démesurés, etc. ${ }^{5}$.

Mais quels sont les traits de la «culture africaine » dont ce passé flou serait porteur et qui expliqueraient, selon le СТA, les particularités des États africains contemporains? On s'aperçoit vite, à y regarder de plus près, que ce soubassement ancestral commun (familial, religieux, social, culturel ou moral) se réduit en fait à une série de quelques idées reçues autour des "conceptions africaines" du monde ou du pouvoir, des "valeurs communautaires", des "pesanteurs magico-religieuses", ou de «la disparition de l'individu derrière la famille ». Les politologues avec lesquels nous allons illustrer le стА (Schatzberg, Chabal et Daloz) se focalisent ainsi particulièrement sur le rôle central des forces occultes, de la parenté ou de l'ethnie, comme référents culturels de l'action politique.

\section{La matrice morale de Schatzberg}

Schatzberg $(1993,2001)$, par exemple, centre son propos sur l'existence, selon lui, d'une "matrice morale» qui serait sous-jacente aux comportements politiques, ceux des élites comme ceux des agents de l'État ou même des simples citoyens. Cette matrice, fondamentalement culturelle, définirait un cadre cognitif commun pour une société toute entière (en l'occurrence, la société congolaise, mais il généralise sans cesse à l'Afrique centrale, et envisage souvent une extension à l'Afrique subsaharienne) : " The matrix is really a series of cultural predispositions and implicit understandings that provide some underlying cognitive structure to those political words, concepts, images, institutions and behaviors that we consider to be thinkable and thus legitimate" (Schatzberg $2001:$ :215).

15 Ce surprenant postulat d'un univers sous-jacent du moral et du pensable qui serait commun aux Africains n'est alimenté empiriquement que par le relevé systématique dans la presse de quelques métaphores récurrentes (présentes aussi dans le langage 
quotidien). «In these uses of specific metaphors (father, family, food), we can discern the continuous elaboration of a moral matrix of legitimate governance-those implicit and culturally accepted tenets which structure perceptions of what is politically acceptable behavior» (ibid. 1993: 450). Les expressions, les allusions ou les images concernant la paternité, la famille ou la nourriture ne manquent certes pas! La méthode est imparable, puisque toutes les autres formes du langage politique dans les médias sont ignorées: le corpus de données est rabattu sur la pêche aux seules métaphores qui confirment la thèse de l'auteur. Le saut sur-interprétatif est évident: on décrète que les Africains partagent une même conception de la légitimité politique, centrée sur l'image du père, et on l'exemplifie sur la base d'un recueil de citations de presse hétéroclites : "Political legitimacy in much of Sub-Saharan Africa is based on the tacit normative idea that governments stands in the same relationship to its citizens as a father does with his children » (ibid. : 455). Ce type de comparatisme, où un auteur poursuit son idée en ne sélectionnant à droite et à gauche que ce qui l'arrange sans se soucier des contre-exemples, dans un corpus extensible à l'infini pour les besoins de sa démonstration, est hélas assez répandu dans les analyses qualitatives de la science politique comparée ${ }^{6}$.

Une telle argumentation ne serait-elle pas aussi favorisée par les " effets d'exotisme " que l'Afrique évoque en permanence chez les intellectuels occidentaux, et qui semblent parfois autoriser, dans le monde de l'africanisme, des relâchements méthodologiques et des invraisemblances théoriques qu'il serait autrement plus difficile de faire passer dans des contextes savants européanistes par exemple?

On relèvera aussi l'usage central, et très particulier, qui est fait des métaphores, mobilisées pour donner une saveur savante aux stéréotypes qui fondent l'argumentation. Certes, les métaphores portant sur le fait de «manger », ou sur la parenté sont courantes dans les langues africaines, ou les parlers français ou anglais d'Afrique. Mais Schatzberg ne s'intéresse pas aux variations de leur champ sémantique et aux multiples contextes de leurs occurrences, il les prend au pied de la lettre, et ne retient que les significations qui l'arrangent: ainsi, pour les métaphores autour de " manger ", seule la signification " occulte " (la dévoration sorcellaire) l'intéresse, elle est systématiquement et unilatéralement privilégiée par Schatzberg, parce qu'il peut la rabattre sur le registre politique pour les besoins de sa démonstration, alors que cette expression entre dans des registres de signification multiples dont la plupart n'ont aucun rapport avec l'occulte ${ }^{8}$.

18 Paradoxalement, Schatzberg se réfère à Lakoff pour assimiler les métaphores de la dévoration ou de la parenté à des "métaphores cognitives». Or, nous pensons au contraire qu'il s'agit, en l'occurrence, de ce que Lakoff (1985) appelle des « métaphores naturelles ». Cette tendance à sélectionner systématiquement et unilatéralement certaines métaphores naturelles éparses dans les discours quotidiens (parmi bien d'autres possibles) et à les « durcir » pour en faire les expressions d'une vision africaine du monde ou du pouvoir, est en effet typique du CTA .

\section{Chabal et Daloz : l'État non émancipé}

19 L'ouvrage de Chabal et Daloz (1998) rejoint sur divers points l'argumentation de Schatzberg et développe lui aussi une posture de type CTA. Certes, il ne peut s'y réduire, dans la mesure où il est plus général, complexe, et ambitieux (il développe parfois, dans 
certains domaines, des analyses assez différentes du CTA, ou énonce des postulats méritant l'attention, mais nous ne développerons pas ces constats ici). L'État moderne africain est pour eux largement inexistant, malgré quelques apparences: «The State in Africa is not just weak but essentially vacuous » (Chabal \& Daloz 1998 : 1), ceci fondamentalement parce qu'il est envahi de part en part par la société : il ne s'est pas affranchi des pesanteurs sociales. "The state in Africa was never properly institutionalized because it was never significantly emancipated from society " (ibid.: 4). Les comportements patrimoniaux, clientélistes, ou corruptifs bien connus trouvent donc leurs racines dans la société, c'est-à-dire dans la culture et dans les normes traditionnelles, qui sont omniprésentes au cœur de l'État, et régulent les formes de légitimité : «In the post-colonial context, political legitimacy derives from a creatively imprecise interaction between what might be termed "ancestral" norms and the logic of the "modern" state " (ibid. : 9). appellent l'instrumentalisation du désordre, se retrouvent en fait plus ou moins les mêmes stéréotypes que chez Schatzberg. Ces stéréotypes typiques du стA tournent autour de quelques mots-clés : relations personnelles, communauté, ethnie, sorcellerie. L'Afrique est le monde des relations personnelles: «In most African countries, the state is no more than a décor, a pseudo-Western façade masking the realities of deeply personalized political relations » (ibid. : 16).

23

vidu n'existe pas en Afrique, seule compte la communauté : "In other words, individuals are not perceived as being meaningfully and instrumentally separate from the (various) communities to which they belong » (ibid. : 52) ; « Representation in Africa is necessarily communal or collective. The legitimacy of the representative is thus a function of the extent to which s(he) embodies the identities and characteristics of the community (ibid. : 55).

L'ethnie est au centre de toute légitimité et de toute redevabilité : "It suggests, contrary to thirty years of Africanist social science, that ethnicity will need to find proper expression if accountability is to return to the post-colonial political order in Africa » (ibid. : 60) ; « Politics must be based on, rather than avoid, the ethnic dimension of the present African nation-state» (ibid. : 62).

Le monde occulte, la croyance aux ancêtres et la sorcellerie régulent de façon souterraine les pratiques politiques: "The world of overt politics is thus deeply influenced by the subterranean realm of the irrational » (ibid. : 65); «Central to African beliefs is the link between the world of the living and that of the dead " (ibid. : 66).

De telles idées reçues cumulent trois procédés typiques du CTA: le réductionnisme exotisant, la généralisation arbitraire, et l'imputation causale abusive.

Tout d'abord, elles réduisent l'Afrique à ses traits exotiques, ceux qui apparaissent comme les plus éloignés des normes sociales occidentales courantes. Bien sûr, il ne s'agit pas pour nous de nier le rôle social que peuvent jouer en diverses circonstances, parfois souvent, les relations personnelles, la pression des insertions communautaires, l'utilisation par des entrepreneurs politiques du facteur ethnique, ou l'importance des croyances magico-religieuses. Et les stéréotypes peuvent avoir une part de vérité. Mais ces phénomènes sociaux, qui font incontestablement partie du paysage quotidien, sont bien loin de remplir celui-ci à eux tout seuls. D'innombrables autres dimensions des

Cahiers d'études africaines, 198-199-200 | 2010 
relations sociales se manifestent partout, des représentations et croyances différentes sont partout identifiables, partout d'autres normes et d'autres registres de l'identité peuvent être analysés. L'Afrique est aussi un lieu d'inventions permanentes, de syncrétismes, d'incorporation de la modernité, d'importations religieuses, de migrations à moyenne et longue portée, de boom associatif, de business petit et grand, de syndicalisme, de tentations prétoriennes, etc. Pourquoi cette réduction de l'Afrique à ses seuls aspects les plus exotiques, et pourquoi ceux-ci en exprimeraient-ils l'identité profonde?

En second lieu, ces stéréotypes produisent des énoncés échappant à tout contrôle empirique. Du fait de leur généralité, et de l'absence de toute argumentation historique sérieuse, les assertions abruptes et catégoriques qui sont assénées tout au long de l'ouvrage et dont nous avons donné quelques exemples ci-dessus agrègent des phénomènes complexes, contradictoires, ambivalents dans des concaténations simplificatrices et même simplistes, sans laisser aucune place aux contre-exemples ou aux cas négatifs, autrement dit sans permettre un débat empirique sérieux. Le culturalisme est une paresse scientifique, qui substitue des présupposés à l'enquête.

Enfin, les clichés culturalistes se prétendent explicatifs du fonctionnement des États. Quelle que soit la part éventuelle de vérité factuelle qu'ils puissent contenir, ils sont abusivement présentés comme une "cause » du comportement des agents de l'État. Quel politologue européen oserait soutenir que, du fait de l'importance des horoscopes dans les médias français, les signes du zodiaque sont régulateurs des pratiques politiques hexagonales?

Prenons cette assertion quelque peu étonnante sous la plume de chercheurs en sciences sociales : « In some fundamental way, therefore, this faith in the power of the irrational is much more than a belief : it is part of the very fabric of the African psyche » (Chabal \& Daloz 1998 : 68). Elle cumule les trois caractéristiques décrites ci-dessus : l'Afrique est réduite à ses croyances occultes; ces croyances seraient au centre de la psychologie africaine (sic!) ; et voilà entre autres pourquoi l'État africain resterait une façade !

31 Le même mécanisme est à l'œuvre dans cette phrase de Schatzberg $(2001: 23)$ : «The imagery and language of father and family are pervasive in middle Africa because they strike a resonant and deeply embedded cultural chord. They form part of a culturally valid and mostly implicit comprehension of the limits of political legitimacy based on a complex and generally unarticulated moral matrix of legitimate governance derived from an idealized vision of patterns and authority and behavior within the family.» L'Afrique est réduite au langage du père et de la famille ; cette idéologie familiale serait au centre de la partition culturelle et de la matrice morale africaines; et c'est là que résiderait l'explication de la légitimité politique !

Pourtant, la représentation du rapport entre le pouvoir et les populations comme étant construite idéologiquement sur le modèle du rapport entre un père et ses fils n'a rien de spécifiquement africain, et ne renvoie pas nécessairement à des traditions précoloniales : une démarche historique conséquente relèvera ainsi à quel point ce modèle a été au cœur de l'idéologie coloniale (les indigènes étant considérés comme de grands enfants que le Blanc se devait d'éduquer). Jean-Pierre Dozon (2003 : 167) relève ainsi que c'est le plan Sarraut, dans les années 1920, qui, dans les colonies françaises, en " introduisant la métaphore du lien familial », a développé le projet d'« organiser une sorte de grande famille au sein de laquelle l'État français jouerait le rôle du père protecteur $"$. 
est de même des catégorisations ethniques, dont il a été montré depuis longtemps à quel point elles étaient le produit des obsessions classificatoires de la colonisation plus que d'être des héritages du passé (Amselle \& M'Bokolo 1985). Jean Bazin (1985: 112 ), après avoir procédé à un inventaire sémantique approfondi des significations associées à l'«ethnie" bambara au Mali, concluait ainsi sa démonstration: «L'invention de l'ethnie procède en effet à contre-sens (ou à court circuit) d'un tel inventaire sémantique. Pour que le nom accède à son statut ethnologique, à sa fonction de désignation d'une entité unique, les Bambaras, il faut lui retrancher du sens, l'appauvrir de son ambiguïté par des opérations de prélèvement, de sélection, de censure qui lui confèrent l'univocité.» pertinentes dans l'analyse des conflits politiques. Mais cette pertinence occasionnelle, qui n'est d'ailleurs pas une spécificité africaine (on pense bien sûr à la Belgique ou aux Balkans), est très variable selon les régions, les époques, les contextes (la colonisation anglaise a plus favorisé le registre ethnique que la colonisation française). Loin d'être un déterminisme culturel hérité du passé, elle s'explique toujours par l'activité d'entrepreneurs ethniques contemporains, et coexiste toujours avec la manipulation d'autres types d'identités collectives (religieuses ou sociales) et les effets d'autres types d'allégeances (factionnalismes et clientélismes). Nassirou Bako-Arifari (1995) a montré que la « logique du terroir » chez les politiciens béninois remonte au régime Kérékou et s'est développée sous la démocratisation, avec la stratégie des politiciens de se présenter comme des «fils du pays» et de susciter ainsi des solidarités locales et régionales.

ons a contrario un exemple, issu de nos propres travaux sur les services publics en Afrique de l'Ouest. L'une des caractéristiques dominantes de leur fonctionnement (une de leurs normes pratiques) est l'absence généralisée de fonctionnement en équipe, autrement dit un individualisme professionnel omniprésent (que nous avions appelé le " chacun-pour-soi-isme») (Olivier de Sardan 2004). Pourtant le CTA met, quant à lui, systématiquement en avant la pression communautaire, la suprématie du collectif sur l'individu, les solidarités primordiales. Bien évidemment la pression communautaire existe, mais dans certains domaines et dans certains contextes. Elle est en outre l'objet de stratégies de contournements et de ruses de la part des intéressés. Et surtout elle est loin d'être la seule norme en piste. Dans de nombreux domaines (et pas seulement au sein de la fonction publique) les comportements hyper-individualistes et les stratégies opportunistes sont importants, parfois plus qu'en Europe. Au nom de quoi décrétera-ton alors que la solidarité communautaire seule est une valeur profondément africaine, en « oubliant » par là même toutes les autres normes concurrentes ou alternatives ?

Dans un ouvrage ultérieur, Chabal et Daloz (2006) tentent de légitimer théoriquement leur posture culturaliste, allant jusqu'à l'assimiler à la perspective " interprétativiste " en sciences sociales. Certes, ils sont plus prudents dans leurs affirmations, proclament ne pas avoir une vision mécaniste de la culture, et en proposent une définition "geertzienne" (voir infra), à orientation sémiologique, en tant que "system of meanings » (ibid. : 22). Ils tentent d'opposer cette acception aux termes habituels de "valeurs, croyances et normes ", afin de se démarquer de l'ouvrage de Harrison et de Huntington (2000), Culture Matters. Cependant ce démarquage reste largement rhétorique, car, de fait, les systèmes de significations qu'ils citent en exemples recouvrent chez eux plus ou moins ces mêmes réalités que d'autres dénomment 
valeurs, croyances et normes, et ils se déplacent au pas de course dans un espace complexe et touffu de généralités, d'affirmations de principe, d'exhortations épistémologiques et de références érudites offrant peu de prises à une discussion productive.

Les lecteurs critiques y ont d'ailleurs retrouvé les mêmes travers que dans l'ouvrage précédent. Par exemple, pour Kate Meagher (2006: 591), une anthropologue particulièrement polémique, on a toujours affaire à une " unshamedly essentialist view of culture ». "We are told that culture is not a product of institutional history or political agency, but arises from communal "codes" embedded in society: human beings inherit cultural codes from birth, they are passed on to their descendants " (ibid. : 86). "Cultural change is reduced to a notion of how ancient codes shall responses to modern situations" (ibid.: 591). Elle dénonce une «[...] tabloid view of African political culture based on prejudice and stereotypes rather than on anything approximating evidence. The key regulatory forces in African politics are identified as ethnicity, clientelism, sexual predation and witchcraft » (ibid. : 592).

\section{L'anti-culturalisme}

Nous sommes donc loin d'être les seuls anthropologues à avoir une position critique face au culturalisme de certains politologues africanistes et à mettre en évidence les stéréotypes sur lesquels ils se fondent. Mais il faut reconnaître que, au sein même de la science politique, des positions anti-culturalistes vigoureuses ont aussi été exprimées. Du côté francophone, nous prendrons pour exemple Jean-François Bayart (1996), dont l'ouvrage sur le sujet est d'ailleurs paru avant ceux de Chabal et Daloz, et qui, en conséquence, ne les prend pas pour cible (il ne mentionne pas non plus Schatzberg) ${ }^{10}$. Mais du côté anglophone aussi les critiques sont venues de l'intérieur de la discipline : «Political cultures accounts, with their tendencies toward cultural essentialism, have rightly come in for criticism by many political scientist [...] this understanding of culture as a specific group's primordial values or traits is untenable empirically. It ignores the historical conditions and relevant power relationships " (Wedeen 2007 : 713-715).

39 Jean-François Bayart (1996: 21) se situe à un niveau plus général. Il considère que le culturalisme, qu'il associe à l'idéologie identitaire, est fondamentalement pernicieux, pour des raisons qui sont d'ailleurs chez lui tout autant politiques que scientifiques. Sa question de départ pourrait en tout cas être la nôtre : «Comment penser les rapports entre culture et politique sans être culturaliste?»

40 Son attaque contre le culturalisme s'appuie sur une série d'arguments enchevêtrés qui prennent la forme d'un procès que nous résumerions volontiers à travers les chefs d'accusations suivants: essentialisation, déterminisme, homogénéisation, déhistoricisation, sociétisation.

41 Le culturalisme "définit de façon substantialiste les cultures» (ibid.: 12). Mais le culturalisme entend être aussi explicatif, et Jean-François Bayart conteste sa prétention à constituer une "causalité univoque " (ibid.) de l'action politique. Le culturalisme postule que les cultures sont homogènes, et, de ce fait, «l'interprétation culturaliste omet de restituer la part de la contradiction et du conflit politique » (ibid. : 29). Elle est également a-historique, dans la mesure où «le culturalisme s'entête à considérer qu'une "culture" se compose d'un corpus stable et clos de représentations, de 
croyances ou de symboles" (ibid.: 46). Enfin le culturalisme superpose indûment culture et société, en faisant correspondre une communauté politique et une communauté culturelle. semble parfois se réintroduire chez lui subrepticement par la fenêtre, dans la mesure où cette " politique du ventre ", par laquelle il caractérise parfois l'État en Afrique, se réfère non seulement à la corruption et à la prévarication régnant chez les élites politiques, mais "aussi et surtout » à la sorcellerie: «La "politique du ventre" se rattache non seulement à la problématique pastorale et rédemptrice du pouvoir [...] mais aussi et surtout au répertoire de la sorcellerie, une pratique dont les entrailles sont justement le centre" (Bayart 1996: 122). Bayart rejoint donc paradoxalement Schatzberg, Chabal et Daloz dans la sur-interprétation des métaphores du «manger » par la focalisation sur le seul sens occulte. Certes, la «politique du ventre» ne serait pas pour lui une "culture", mais un «système d'action historique» (ibid.: 120-121); certes, les répertoires de l'occulte ne seraient pas seuls en piste et ils côtoieraient d'autres registres; certes, ils ne seraient pas statiques, mais innovants. Mais ces précautions rhétoriques ne sont pas sans rappeler celles de Chabal et Daloz se défendant eux aussi d'avoir une vision essentialiste de la culture, et soulignant le caractère adaptatif de celle-ci. Et on perçoit clairement tant les surprenantes dérives de l'auteur sur cette question que son propre embarras dans cet extrait: « Cette croyance partagée [la sorcellerie] constitue-t-elle alors la culture de l'Afrique ? Décidément non, si l'on veut dire par là qu'elle forme un bloc homogène et atemporel de représentations qui aurait plus d'importance que les autres répertoires, qui serait en quelque sorte le genre discursif absolu du politique [...]. Néanmoins, les pratiques de l'invisible, si elles ne constituent pas la culture africaine en bonne et due forme, sont sans conteste des pratiques culturelles [...]. Ces pratiques de l'invisible, immédiatement compréhensibles 
pour les Africains, sont l'un des instruments de prédilection par lesquels ils réinventent leur différence dans le processus de globalisation » (Bayart 1996 : 136-137).

Bien évidemment, on ne saurait nier l'importance dans la vie quotidienne des croyances et pratiques liées aux forces occultes en Afrique (mais pas seulement en Afrique). Le problème n'est pas là. Il est dans la place qu'on leur accorde, et ceci sur trois plans.

Soit on les met sans autre forme de procès dans une catégorie unique placée au centre d'une spécificité culturelle africaine affirmée ex abrupto. À juste titre, dans une revue critique de l'inflation de publications académiques anglophones sur la sorcellerie, la magie, les zombies, les maléfices, les hommes-léopards, les royaumes invisibles, les «économies de l'occulte ", etc., Terence Ranger démontre à quel point les chercheurs tendent à agréger en une seule catégorie (" occulte ») des phénomènes en fait de types et d'extensions très variés, ce qui permet de présenter l'Afrique "as the home of occult » (Ranger $2007: 275$ ), et à quel point « many of these studies are ahistorical, with the present unconnected to the past in any meaningfully documented way " (ibid. : 279).

Soit on oublie que les pratiques ou croyances « occultes » coexistent avec bien d'autres « mondes », « répertoires » ou " programmes ». Pourtant, dans un texte célèbre relatif aux rapports entre les Grecs et leurs mythes, et plus généralement à ce que peut dire la sociologie des religions, Paul Veyne (1983: 97) soulignait que «notre vie quotidienne est composée d'un grand nombre de programmes différents [...] nous passons sans cesse d'un programme à l'autre, comme on change de longueur d'onde à la radio, mais nous le faisons à notre insu ». Dans ce sens, le « programme sorcellerie » existe certes, mais n'est qu'un de ceux que tout un chacun active quotidiennement.

Soit enfin on leur donne une valeur explicative des comportements politiques. Mais jamais la démonstration n'est faite, parce qu'elle est impossible. Les enquêtes de terrain montrent au contraire que les croyances en la magie ou la sorcellerie coexistent fort bien, chez les leaders politiques, avec les stratégies factionnelles, les habitudes militantes, les entreprises de patronage, les argumentaires populistes, les coups montés politiciens, les détournements, les achats de vote, et toute la gamme des registres ordinaires de l'action politique, sans qu'on puisse déterminer réellement qu'elles les modifient en quoi que ce soit.

On voit en tout cas combien la question du culturalisme africaniste est complexe, puisque ceux qui le dénoncent y succombent parfois, puisque tous ceux qui s'y adonnent s'en défendent, puisqu'on peut l'être dans un domaine et pas dans un autre, un jour et pas le lendemain, et puisque certains peuvent avoir des propos culturalistes sans employer le mot de culture alors que d'autres qui l'utilisent s'en démarquent autant que faire se peut ${ }^{11}$ ! C'est bien pour cela que le culturalisme savant n'est pas une théorie, mais une pratique, ou une posture, parfois occasionnelle, et où chacun de nous peut à l'occasion succomber ou être suspecté de le faire. Ce n'est en rien un paradigme, qui nourrirait explicitement un programme de recherche revendiqué en tant que tel (bien que Chabal et Daloz semblent parfois le prétendre) ${ }^{12}$. Le CTA peut surgir dans des espaces intellectuels très variés, puisqu'il est d'abord et avant tout une configuration de stéréotypes, autrement dit une idéologie scientifique, compatible avec de multiples positionnements théoriques, qui peut s'exprimer chez des auteurs que sinon beaucoup opposent, ou sévir chez des analystes par ailleurs brillants. Les idéologies scientifiques ont ceci de particulier pour un chercheur qu'on ne peut jamais s'en prétendre soimême totalement indemne : le culturalisme ne fait pas exception, et nul d'entre nous 
ne peut affirmer n'avoir jamais proféré un énoncé situé dans un registre culturaliste, que ce soit en utilisant le terme " culture » ou non ${ }^{13}$. En effet, ce sont les stéréotypes qui s'y cachent qui définissent l'idéologie culturaliste, et non l'usage du terme "culture " en soi. Il est d'ailleurs de nombreux usages approximatifs ou distraits du terme «culture » qui ne relèvent pas du culturalisme, et auxquels tout chercheur peut avoir recours à l'occasion. "Culture" est bien souvent une notion commode et non un concept ou une idéologie, un simple raccourci, qui fait alors figure de «qualificateur vague $»^{14}$, comme nous en utilisons tous, entre autres à des fins pédagogiques. Mais il est aussi des usages rigoureux et non idéologiques de "culture », on y reviendra plus loin.

51 On doit aussi reconnaître au culturalisme des circonstances atténuantes, et beaucoup de bonnes intentions. En effet, dans des contextes de négation des spécificités et identités dominées ou d'occidentalo-centrisme dominant, la prise en compte de la "culture de l'autre» et le respect des coutumes locales apparaissent comme des progrès incontestables. Ceci est vrai du culturalisme populaire, qui se veut souvent découverte, réhabilitation, voire émerveillement, mais aussi du culturalisme savant. Par exemple, Chabal et Daloz (2006) légitiment leur plaidoyer culturaliste par la lutte contre la domination indue du quantitativisme, $d u$ positivisme et des normes occidentales en science politique comparée, par le refus de l'ethno-centrisme, par l'importance de la prise en compte du "point de vue de l'autre ", par la nécessité d'une connaissance des contextes historiques, sociaux, culturels. On ne peut qu'être d'accord avec de telles aspirations. De même, chez certains économistes, l'entrée par la culture est un moyen d'échapper aux formalismes et aux équations de leurs collègues, et de renouer avec le réel (Platteau 2008). Cette sensibilité à la culture comme façon de penser la réalité des autres en sa spécificité est plus qu'honorable: elle est même au fondement des sciences sociales empiriques, et en particulier de l'anthropologie, et nous la partageons tous. C'est le contenu stéréotypé et traditionaliste qui se faufile en contrebande derrière ces bonnes intentions qui pose problème.

Curieusement, cette valeur positive accordée à la (re)découverte contemporaine du terme de culture en science politique ou en économie rappelle le contexte de son émergence en anthropologie, il y a près d'un siècle, où elle est apparue comme une réhabilitation méritoire des savoirs et coutumes des peuples colonisés et un refus nécessaire de la vision évolutionniste du monde. Revenir rapidement sur l'histoire de ce concept ${ }^{15}$, bien au-delà de l'Afrique, peut permettre de comprendre comment, issu de l'anthropologie, il a pu peu à peu devenir emblématique d'une certaine idéologie scientifique, reprise désormais par d'autres disciplines.

\section{Culture et culturalisme en anthropologie}

Non seulement on a pu dire que c'était l'anthropologie (sous son nom aujourd'hui quelque peu démodé de "ethnologie») qui avait inventé le concept sociologique de culture, mais celui-ci en a été en quelque sorte l'emblème théorique. " As early as 1917, Robert Lowie proclaimed that culture "is, indeed, the sole and exclusive matter of ethnology" »(Kuper 2000 : ix).

Aujourd'hui encore, nombreux sont ceux qui sont prêts à définir l'anthropologie comme la science des cultures. Cependant, la signification du concept s'est fortement 
transformée en un siècle. On peut pour l'essentiel distinguer deux grandes étapes : avant et après Parsons.

Au départ, et jusqu'aux années 1950 environ, «culture » s'appliquait de préférence à tous les aspects de la production humaine en société, et englobait les multiples caractéristiques qu'un groupe social (de préférence une "ethnie ", autrement dit un groupe «primitif» de petite taille) pouvait avoir en commun: langue, religions, techniques, art, règles sociales, système de parenté, etc. Pour Tylor «Culture, or civilization, taken in his wide ethnographic sense, is that complex whole that includes knowledge, belief, art, morals, law, custom and any other capabilities and habits acquired by man as a member of society ${ }^{16}$. En ce sens, le concept était tout autant un outil monographique (décrire chapitre après chapitre toutes les dimensions de la culture d'une ethnie) que comparatif (faire le tableau des variations culturelles entre peuples). Au niveau comparatif, l'approche par la culture a eu en son temps un énorme avantage : celui de rompre avec l'idéologie scientifique évolutionniste qui régnait alors. $\mathrm{Au}$ lieu de ranger les sociétés selon une ligne de progression unilatérale aboutissant aux sociétés industrielles (ou aux sociétés communistes, dans la variante marxiste), l'approche par la culture proclamait l'égalité cognitive de toutes les cultures: les unes comme les autres étaient des productions humaines dignes d'estime, toutes se valaient, chacune méritait connaissance et respect. C'était une petite révolution épistémologique, dans laquelle le rôle de Boas a été largement souligné. Mais c'est aussi Boas qui a insisté pour donner à ce concept des contenus aussi empiriques que possible permettant des comparaisons échappant aux spéculations et aux généralisations excessives (Cuche 2004 : 20). On verra qu'il n'a pas été suivi.

Cette rupture fondamentale ouvrait un vaste champ de recherche, en associant durablement «culture » et « relativisme culturel» sous la houlette de l'anthropologie. «En France, c'est sans doute Claude Lévi-Strauss qui a popularisé la portée du relativisme culturel comme principe et instrument de tout travail ethnologique en marquant la rupture qu'il instaure avec "l'évolutionnisme social". Mais cette opposition figurait depuis longtemps parmi les topiques de l'anthropologie anglo-saxonne" (Grignon \& Passeron 1989 : 19).

\section{L'abstractisation du concept de culture}

57 Mais si le postulat du relativisme culturel a permis de rompre avec l'idéologie évolutionniste, il n'était pas lui-même sans avoir ses propres dérives idéologiques ${ }^{17}$. On pourrait ainsi souligner deux risques inhérents à cette démarche, et auxquels, dès ses débuts, elle n'a pas toujours échappé : le risque d'«essentialisation » et le risque de "dé-historicisation ${ }^{18}$. Ces risques ont toutefois été largement amplifiés avec la réorganisation sémantique du concept de culture, qui a, de fait, ouvert la voie à la constitution du culturalisme comme idéologie scientifique stabilisée. Après la Seconde Guerre mondiale, «culture » est en effet devenu un concept au spectre moins large et plus ciblé, mais aussi beaucoup plus abstrait. Désormais, il prend un sens idéel, cognitif, symbolique, sémiologique. Ses significations, en sciences sociales du moins, échappent à la seule ethnologie comparée des sociétés primitives, et au découpage en secteurs multiples de l'activité humaine, et se concentrent sur un domaine virtuel qui, présent dans toutes les sociétés, grandes ou petites, va des «visions du monde » aux " codes partagés ", des "systèmes de valeurs " aux "références morales ». Cette mutation est associée au nom de Talcott Parsons: «It was Parsons who created the need for a 
modern, social scientific conception of culture, and who persuaded the leading anthropologists that their discipline could flourish only if they took on culture in his sense as their particular speciality » (Kuper $2000: 68$ ). La mutation parsonnienne du concept de culture a eu une conséquence épistémologique importante, qui va favoriser l'émergence de l'idéologie culturaliste moderne : elle a coupé le concept de culture de ses ancrages empiriques et de sa multidimensionnalité, et l'a transformé en abstraction holiste.

Auparavant, la culture d'une quelconque ethnie indienne ou polynésienne pouvait (et devait, selon Boas) être décomposée en sous-systèmes nettement circonscrits, comme autant de modules relativement autonomes, chacun d'entre eux étant accessible à des observations et à des descriptions empiriques: rituels, gestuelles, techniques artisanales, mythes, techniques divinatoires, savoirs botaniques, etc. Après Parsons, la culture perd cette accessibilité empirique, elle perd cette plasticité, elle perd cette organisation conceptuelle en modules juxtaposés ad libitum, et devient une pièce centrale dans la vision intégrée et abstraite du monde qui est la marque de fabrique de Parsons. Ce dernier parle donc désormais du « système culturel », comme un système autonome, à côté du « système social ». «A cultural system is not an empirical system in the same sort as a personality or social system, because it represents a special kind of abstraction of elements from these systems [...]. A cultural system is a pattern of culture whose different parts are interrelated to form value systems, beliefs systems, and systems of expressive symbols» (Parsons \& Schils 1990 : 40). Kroeber et Parsons (1958: 582-583) définissent ainsi le concept de culture: "Transmitted and created content and patterns of values, ideas, and other symbolic-meaningful systems. » Le système culturel occupe donc pour Parsons une place virtuelle fort éloignée de toute observation empirique: "Culture" now became an umbrella term for the realm of ideas and values » (Kuper $2000: 53)$. On n'est pas très loin de la notion hégélienne de «l'esprit d'un peuple» (geist) (Alexander $1990: 2$ ).

Comment observer des idées, des valeurs, des visions du monde? Il n'y a pas de descripteurs directs disponibles. Seuls, en effet, des discours peuvent être entendus, des pratiques observées, des objets examinés. On ne peut qu'en inférer, plus ou moins audacieusement, l'existence de "valeurs » qui s'y révéleraient ou s'y cacheraient. Cet univers de la culture telle qu'elle est balisée par Parsons ${ }^{19}$ est un univers à hauts risques sur-interprétatifs. Il est facile pour le chercheur de plaquer ses propres conceptions, ses propres théories, ses propres fantasmes, ses propres clichés sur les indices hétéroclites et épars qu'il constitue en références empiriques. Le piège idéologique du culturalisme savant s'ouvre plus largement avec Parsons.

61 Si la sociologie parsonnienne a abondamment été critiquée pour son fonctionnalisme, son conservatisme implicite, son systémisme, on n'a pas pris la mesure de l'incroyable influence épistémologique sous-jacente que sa définition de la culture a eu sur toutes les sciences sociales, car celle-ci a été très peu contestée, comme si elle " allait de soi ». On la retrouve en particulier présente dans toute l'anthropologie américaine contemporaine, et bien au-delà, aussi bien chez les figures les plus connues et les plus citées (Geertz, Sahlins, Schneider, Rosaldo, Comaroff) que chez les anthropologues postmodernes, qui, dans leurs attaques tous azimuts contre l'anthropologie classique, n'ont significativement épargné que le concept de culture, lequel a bénéficié chez eux d'une impunité quasi-totale. Il est significatif de voir aujourd'hui aux États-Unis le succès des "cultural studies ", devenues quasiment une discipline à part entière, et qui 
n'existent que grâce à la permanence de l'acception parsonnienne du concept de culture, sous des versions modernisées et raffinées ${ }^{20}$.

Clifford Geertz, dans cette transmission souterraine, comme dans le processus de modernisation et de raffinement, a joué un rôle central. Il fut l'un des principaux collaborateurs et disciples de Parsons. Il a installé, avec son talent et son sens des formules, la perspective parsonnienne sur la culture au centre de l'anthropologie américaine contemporaine. Mais il a aussi modernisé cette perspective, en donnant au concept une orientation plus sémiologique, comme étant constitué de "réseaux de significations ». Il ne s'agit en aucun cas d'une rupture, mais d'un raffinement. On l'a vu ci-dessus, les «symbolic meaningful systems » faisaient partie de la définition de la culture pour Parsons ${ }^{21}$. Schneider (1976: 107) a, de son côté, défini celle-ci comme « a system of symbols and meanings ".

D'autres variations feront de la culture une structure cognitive, une grammaire, un système de $\operatorname{codes}^{22}$. Sans se référer particulièrement à Parsons, Jack Goody (1993:11) a constaté qu'aujourd'hui le concept de culture relève d'une « autonomy of an ideational sphere». "The term tends nowadays to be associated with "systems of signs and symbols" or "structure of meanings". Their study thus becomes dissociated from the objects, relationships, processes " (ibid.: 11). Désormais, la culture est logée dans les esprits ou les cœurs, loin de toute observation empirique (Sanday 1979: 534). Il est d'ailleurs frappant de constater à quel point l'expression de "system of meanings ", qui a connu un grand succès depuis une trentaine d'années, et que reprennent inlassablement Chabal et Daloz, est en fait, dans les usages qu'en font tous ceux qu'y s'y réfèrent, un concept flou, polymorphe, aussi général qu'imprécis, de type «auberge espagnole $»^{23}$.

\section{Culture et grand partage}

64 Un autre aspect non négligeable de l'héritage intellectuel latent de Parsons, qui a joué un rôle dans la «traditionalisation » du concept de culture, est sa fameuse dichotomie entre sociétés et cultures traditionnelles et sociétés et cultures modernes, à laquelle il a donné une grande importance, car elle était censée rendre compte des phénomènes de changement ou de résistance au changement ${ }^{24}$. Certes, une telle opposition se retrouve dans toute l'histoire des sciences sociales dans des styles et sous des vocables variés. Elle avait été formulée il y a longtemps par Tönnies opposant gesellschaft (association) et gemeinschaft (communauté), ou par Durkheim opposant solidarité organique et solidarité mécanique, mais elle a pris sa forme moderne avec Parsons, qui l'a d'une certaine façon "culturalisée » et "stéréotypée». On constate en effet que les caractéristiques idéal-typiques qui opposent le traditionnel et le moderne chez Parsons, et qui ont été reprises par bien d'autres que lui jusqu'à nos jours, ne sont pas tant le produit d'enquêtes empiriques qu'ils ne relèvent de stéréotypes savants s'apposant terme à terme: le monde du traditionnel recouvre ascription, communauté, homogénéité, don, relations de clientèle, routine, solidarité, informel alors que le monde du moderne inclut achievment, individu, hétérogénéité, argent, relations bureaucratiques, innovation, concurrence, formel. En tant que valeurs ou systèmes de sens, la «culture traditionnelle » qui est derrière un versant de ces termes reste avec Parsons une antithèse de la culture moderne, qui est derrière l'autre. Dans les sciences sociales comme dans le sens commun, "culture» reste aujourd'hui encore très fréquemment associée à «tradition", malgré les transformations parsoniennes- 
geertziennes du concept. Par exemple, l'article « culture » du Dictionnaire de l'ethnologie et de l'anthropologie rappelle que la culture "c'est ce qu'on trouve en naissant " (Izard 2000 : 190), insiste sur sa transmission, et évoque avec insistance à son sujet les mots de «tradition", «coutume», " héritage ». L'idéologie culturaliste traditionaliste africaniste (le стA) se situe dans une telle lignée.

Cette dichotomie récurrente traditionnel/moderne a été critiquée depuis longtemps sous le nom de "grand partage» (great divide) (Latour 1983 ; Lenclud 1992). Une des caractéristiques du " grand partage », dont on a souligné plus haut qu'elle était au cœur $\mathrm{du}$ СТА, est l'oubli de toute perspective historique, laquelle, d'ailleurs, rendrait intenable cette dichotomie: les sociétés et cultures contemporaines dites traditionnelles sont en effet tout autant que les sociétés et cultures dites modernes l'aboutissement de processus historiques complexes, qui mêlent et lient ces deux catégories autant sinon plus qu'ils ne les opposent.

Plus généralement, la transformation progressive du concept de culture en idéologie scientifique n'a pas été sans rencontrer, au sein même de l'anthropologie, des oppositions résolues.

\section{Contre l'uniformisme}

Kuper, qui a fait la meilleure histoire du concept de culture, le dit assez brutalement "Even in sophisticated modern formulations, culture - or discourse - tends to be represented as a single system [...]. However, to understand culture, we must first deconstruct it [...]. In short it is a poor strategy to separate out a cultural sphere and to treat it in its own terms » (Kuper $2000: 247)$.

Une des critiques les plus intéressantes est celle de Pelto \& Pelto qui appellent pour leur part « uniformisme » ce que nous dénommons idéologie culturaliste : «We will use the term "uniformism" as a label for referring to the various descriptions and theories that are based on an idea of a common, shared, homogeneous culture, or on culture as the set of standards, rules or norms » (Pelto \& Pelto $1975: 1-2)$. Ils se focalisent sur les effets d'homogénéisation propres à cette posture, et soulignent qu'ils ne s'appliquent pas seulement aux sociétés dites "primitives", mais aussi aux sociétés paysannes modernes (ibid. : 4). Une des illustrations les plus connues en ce domaine est la théorie de Foster (1965) sur "the image of limited good», qui propose au fond une sorte de "matrice morale» commune aux sociétés paysannes, et a fait l'objet de nombreux débats (Bennett 1966 ; Kaplan \& Saler 1966 ; Foster 1972; Hutton \& Robin 1975). Nous pourrions dire que le culturalisme africaniste élargit quant à lui démesurément le périmètre de l'uniformisme culturaliste, en l'étendant bien au-delà des sociétés dites primitives et des sociétés paysannes, et en englobant sans hésitation les fonctionnaires des villes africaines comme les élites politiques du continent.

Pelto et Pelto proposent divers facteurs explicatifs quant au succès de l'uniformisme culturaliste, parmi lesquels la propension humaine aux stéréotypes et le fait de travailler sur des cultures exotiques. Ces deux facteurs sont en effet largement imbriqués dans le cas du cTA. 


\section{Retour à l'Afrique}

70 Dans ce très rapide survol de l'histoire du concept de culture en anthropologie, on aura peut-être remarqué que ne figurent pas parmi ses promoteurs de références africanistes. Certes, l'ethnologie coloniale n'a pas manqué de perspectives culturalistestraditionalistes, tels les écrits « indigénistes » des administrateurs coloniaux célébrant "l'âme nègre " (Dozon 2003 : 222) 25. L'œuvre de Marcel Griaule en est l'illustration la plus érudite et la plus connue du côté francophone. Mais, paradoxalement, ce sont des politologues qui ont réactivé récemment le CTA alors que les anthropologues africanistes modernes ont été relativement peu culturalistes. Il faut y voir pour une bonne part l'influence de l'école de Manchester, qui a durablement marqué le paysage de l'anthropologie africaniste anglophone comme francophone. Malgré d'incontestables limites, elle a été innovante dans de nombreux domaines, elle a pris en compte le contexte colonial, et a mis l'accent sur les dynamismes, les processus, les réseaux et les interactions, s'éloignant ainsi des visions culturalistes et traditionalistes propres à l'ethnologie classique et coloniale ${ }^{26}$. Du côté francophone, Georges Balandier, le principal promoteur des études africaines modernes en France, et l'un des principaux résistants à la vague structuraliste des années 1960-1980 (laquelle n'était pas sans parfois verser dans le culturalisme), a repris à son compte et développé ces acquis de l'école de Manchester ${ }^{27}$.

71 De fait, les deux effets pervers majeurs du culturalisme, l'effet de cohérentisation (l'uniformisme critiqué par Pelto \& Pelto) et l'effet de traditionalisation (les dichotomies du grand partage) ont été l'un et l'autre dénoncés largement par les anthropologues africanistes, quels que soient leurs domaines de recherche ou leurs références théoriques. Par exemple, dans les années 1960 à 1980, l'anthropologie économique marxiste africaniste a insisté sur les divisions internes propres aux sociétés locales africaines (aînés/cadets, esclaves/aristocrates, etc.) et sur leur articulation avec le monde colonial et l'économie capitaliste ${ }^{28}$. Plus récemment l'anthropologie du développement comme l'anthropologie de la santé ont critiqué les explications culturalistes avancées quasi systématiquement par les opérateurs de développement ou les spécialistes de santé publique en Afrique pour rendre compte des comportements qui échappaient à leurs modèles ${ }^{29}$.

Mais c'est une comparaison proposée par Jack Goody qui constitue à nos yeux la plus sévère critique du CTA, bien qu'elle soit indirecte et ne contienne pas la moindre polémique. En effet Goody compare le travail de l'anthropologue travaillant en Afrique sur de petites sociétés ethniquement homogènes et encore relativement « traditionnelles » (comme les Nuer ou les Tallensi) et celui de l'historien, Keith Thomas (1971), portant sur l'Angleterre à l'époque des Tudor. Il remarque tout d'abord que les Nuer et les Tallensi sont certes plus homogènes culturellement que l'Angleterre du Xvi siècle; mais note cependant que: "Even for these simpler societies it is easy to overemphasise the homogeneity of culture, which is always relative " (Goody $1993: 14$ ). Puis, il développe la comparaison : "In the introduction, he [Keith Thomas] writes of the diversity of England at that period due to the "huge variations in standard of living, educational level and intellectual sensibility which makes this society so diverse and therefore so hard to generalize about [...]. The task of the historian is thus infinitely harder than that of the social anthropologist, studying a small homogeneous community in which all inhabitants share the same beliefs and where few of those 
beliefs are borrowed from other societies. This was not simple unified primitive world, but a dynamic and infinitely various society, where social and intellectual change had long been at work and where currents were moving in many directions" (Thomas 1971 : 5) » (Goody $1993: 14)$. Or, aujourd'hui, l'Afrique qu'étudient les chercheurs, qu'ils soient anthropologues ou politologues, est infiniment plus proche de la complexité et de la diversité de l'Angleterre des Tudor (elle est même autrement plus complexe et diverse) que de la (relative) homogénéité des Nuer ou des Tallensi avant l'indépendance. Tout ce que dit ici Goody de l'Angleterre s'applique parfaitement à l'Afrique contemporaine.

Mais alors faut-il abandonner tout usage du concept de culture?

\section{Un usage raisonné, circonscrit et empiriquement attesté de «culture»}

74 À lire Jean-François Bayart, et bien qu'il utilise lui-même souvent l'adjectif « culturel » (« répertoire culturel», " pratique culturelle», « innovation culturelle»), on a le sentiment que les usages culturalistes du mot "culture » ont pollué le concept luimême, qui ne serait plus guère utilisable du fait des innombrables effets pervers dont il est devenu porteur.

Nous ne pouvons le suivre dans ce rejet. Revenons à Goody (1993:18), qui nous servira de point de départ : ce dernier pose en effet la question centrale de ce qui est ou non partagé : «The question of commonality. Who is sharing what?» Il précise toutefois qu'il s'agit de considérer la culture comme un «system of shared meanings and values » (ibid. : 18). Sur ce dernier point, l'affirmation est contestable, même si elle est dans l'orthodoxie parsonienne et évoque les définitions de Geertz et de Goodenough. Valeurs et significations sont en effet des objets théoriques peu susceptibles de vérifications empiriques, qui se situent à un niveau d'abstraction tel qu'ils peuvent englober tout et n'importe quoi, et donc, par là même, qui rendent insoluble le problème de la « commonality » ou du partage que lui-même vient de poser !

Déterminer (au moins à peu près) qui partage avec qui quelles pratiques et/ou quelles représentations sociales est un enjeu scientifique capital. D'une part, il est nécessaire de réintroduire les pratiques, qui sont observables, dans une définition de la culture devenue trop idéelle et évanescente. D'autre part, le concept de représentations sociales a l'avantage de rester proche des discours proférés et se fonde sur ceux-ci : c'est ce en quoi il est empiriquement attestable et relève de l'émique (Olivier de Sardan 2008 : ch. 3), à la différence de concepts tels que "valeurs", "visions du monde", " matrice morale ", " systèmes de sens ", etc. L'anthropologie, aussi qualitative soit-elle dans sa méthodologie, et aussi éloignée soit-elle des standards de représentativité statistique, ne peut éluder le problème du partage des pratiques et représentations. Même de façon très approximative, même en donnant des ordres de grandeur, même en utilisant des "quantificateurs vagues", elle doit préciser le périmètre social des énoncés qu'elle profère, et leurs ancrages dans des contextes spatio-temporels donnés, sous peine d'être accusée à bon droit de généralisations hâtives et injustifiées (lesquelles, il faut le reconnaître, constituent hélas son péché mignon). La science politique relève des mêmes exigences.

Or, la décision du chercheur d'imputer à tel ou tel groupe social un ensemble de pratiques ou de représentations, au moins à titre de dominantes ou de modales, ou 
même ne serait-ce qu'en tant que significativement convergentes, doit être fondée sur des données plausibles, qui sont "nécessairement dépendantes des contextes d'occurrence " (Passeron 1991). Ceci est un garde-fou d'autant plus indispensable que les sciences sociales ont depuis longtemps reconnu que les sociétés dites « complexes " se caractérisent par une multiplicité de rôles, et que chaque individu en assume plusieurs à tour de rôle. La sociologie phénoménologique de Schutz (1987), suivie aujourd'hui sur ce point par la sociologie pragmatique de Boltanski et Thévenot (1991), a exprimé à sa façon ce constat, en parlant d'une pluralité de mondes, entre lesquels circulent les acteurs sociaux, au fil des jours ou des heures. Dans d'autres langages théoriques, on dira que les acteurs sociaux recourent à divers référentiels, ou suivent des logiques plurielles, ou changent de programme (voir l'allusion à Paul Veyne, cidessus), ceci en fonction des situations. La conséquence en est que, dans les sociétés dites complexes, il n'y a plus désormais de "partage culturel étendu» (Hannerz 1992 : ch. 3), comme il y a pu y en avoir dans les sociétés dites primitives. Le partage de pratiques ou de représentations est toujours multiple et mouvant et doit toujours être contextualisé. Or, l'Afrique est aujourd'hui, et depuis longtemps, du côté des sociétés complexes. C'est ce que semblent oublier les tenants, même occasionnels, du сTA.

On peut évoquer aussi le "principe de coupure » dégagé par Bastide (cité dans Cuche 2004 : 61) lors de ses travaux sur le candomblé au Brésil : les acteurs vivant dans une société pluriculturelle découpent le monde social en compartiments étanches, et vivent avec certains codes dans un domaine, et de tous autres codes dans un autre (Cuche 2004 : 61). Aujourd'hui, toutes les sociétés sont multiculturelles, et en Afrique autant sinon plus qu'ailleurs.

On voit à quel point la détermination de la "commonality" des pratiques et représentations est une mission impossible à l'échelle d'un pays, et plus encore d'un continent. De même, c'est une ambition déraisonnable que de vouloir appréhender l'ensemble des "idées", de la "moralité », des "valeurs", ou des "réseaux des significations » d'un groupe quelconque, quel que soit son périmètre. Ce sont pourtant des présupposés culturalistes courants.

En revanche, la question du partage des pratiques et des représentations fait sens si l'on se limite à certains domaines précis, à certains contextes définis, et à certains groupes sociaux ou professionnels circonscrits. Le partage est fonction des rôles, des mondes sociaux, des logiques à l'œuvre. Ce changement d'échelle et cette délimitation du domaine permettent alors d'appréhender des pratiques et des représentations communes qui se construisent et se reproduisent dans des chaînes d'interactions concrètes, observables, descriptibles. Par exemple, des enquêtes approfondies (de terrain de préférence, mais aussi documentaires ou quantitatives) sur les agents des Eaux et Forêts au Sénégal ou sur les élections au Bénin, si elles mettent en évidence des convergences et des rémanences significatives, peuvent permettre de dégager les caractéristiques d'une "culture professionnelle des agents des Eaux et Forêts au Sénégal» (voire même de plusieurs sous-cultures en leur sein), ou d'une "culture électorale au Bénin » (voire même de plusieurs sous-cultures), sans trop de risques de sur-interprétation ou de généralisation abusive, et sans postulat a priori de traditionalité. Cette perspective rejoint d'une certaine façon ce que nous avons appelé ailleurs l'« interactionnisme méthodologique » (par opposition à l'« interactionnisme idéologique »). Elle suppose aussi une analyse historique précise, fine, sectorialisée. Mais elle n'est pas incompatible avec, par la suite, une montée en généralité 
progressive, mais contrôlée, susceptible de dégager ces "théories à moyenne portée " que Merton appelait de ses vœux. L'homologie de résultats avec d'autres études du même ordre menées dans d'autres pays, situés dans des contextes similaires, pourra en effet permettre éventuellement des assertions de niveau plus élevé sur la (ou les) culture(s) professionnelle(s) des agents des Eaux et Forêts au Sahel, ou sur la (ou les) culture(s) électorale(s) dans les démocraties d'Afrique de l'Ouest. Nous rejoignons aussi Hannerz (1992), qui plaide pour des concepts tels que celui de « micro-culture » (fondé sur des expériences concrètes partagées) et « sous-culture » (plus large, et relevant de jeux de relations particulières). Les travaux sur les cultures organisationnelles ou institutionnelles vont dans le même sens.

81 Notre perspective débouche donc sur une définition de la culture comme un ensemble de pratiques et de représentations dont des enquêtes auront montré qu'elles étaient significativement partagées par un groupe (ou un sous-groupe) donné, dans des domaines donnés, et dans des contextes donnés ${ }^{30}$.

Nous pensons par exemple qu'il est légitime de parler d'une culture professionnelle commune des sages-femmes au Niger, sur la base de nombreux travaux empiriques qui ont été menés (Jaffré \& Prual 1993 ; Souley 2003 ; Moumouni \& Souley 2004), et qui ont mis en évidence tout un ensemble de normes pratiques convergentes telles que: le sentiment d'appartenir à une élite sociale et professionnelle, un certain mépris pour l'ignorance des parturientes, la banalisation de la profession et la disparition de la notion de « vocation » et de ses implicites éthiques, le sentiment que leur expérience et leur flair valent mieux que le savoir des médecins, une appropriation à leur profit de l'espace et du temps dans les maternités, un sentiment d'impunité, la recherche de ressources complémentaires aux dépens des parturientes, une forte délégation des tâches aux matrones, filles de salle et stagiaires, le primat des formes de sociabilité féminine sur les exigences professionnelles, la quête de formations continues indépendamment du contenu de celles-ci, l'apprentissage de ces normes pratiques à travers les stages lors des études et la première année d'exercice de la profession, etc.

Cette culture professionnelle est très éloignée des normes officielles, mais aussi des attentes des populations, et n'a rien à voir avec les clichés du CTA: les facteurs ethniques, la sorcellerie ou la parenté ne sont pas des éléments explicatifs pertinents des comportements des sages-femmes aujourd'hui (même si celles-ci, bien sûr, dans leur vie privée, ont des attaches communautaires, consultent les devins, et sont dans des réseaux familiaux, comme tout le monde). Les traditions précoloniales en matière d'accouchements (à domicile) sont à l'opposé de cette culture professionnelle: les accoucheuses, qui étaient surtout des "coupeuses de cordon", étaient des vieilles femmes proches de la parturiente jouant surtout un rôle d'appui, d'encouragement, de soins post-partum (lavage de l'accouchée, enterrement rituel du placenta).

Cette culture professionnelle déborde même le Niger, et peut être étendue à l'Afrique de l'Ouest, sur la base de travaux empiriques aboutissant aux mêmes conclusions (Koné 2003 ; Jaffré \& Olivier de Sardan 2003 ; Vasseur 2004 ; Jaffré et al. 2009) ${ }^{31}$.

Un tel usage mesuré et circonscrit du concept de culture, gagé sur des travaux empiriques, permet d'échapper à la vague des stéréotypes exotiques, comme elle permet d'échapper à l'illusion passéiste. En effet, les enquêtes approfondies menées sur des cultures professionnelles, religieuses, locales, générationnelles, de genres, politiques ou institutionnelles ${ }^{32}$ nettement circonscrites contredisent les clichés et font voler en éclats les présupposés culturalistes. Elles révèlent à quel point la tradition 
précoloniale a été bouleversée en Afrique, combien est important le poids de l'héritage colonial, quels effets pervers ont entraîné l'aide au développement. Elles mettent aussi en évidence les innombrables réponses et innovations propres à la modernité africaine, et soulignent la diversité et l'hétérogénéité des référents sociaux, politiques, familiaux ou religieux contemporains. Toutes les «survivances" précoloniales que le CTA mobilise ad nauseam (comme la famille, l'ethnie, la solidarité communautaire, les pratiques thérapeutiques populaires ou le magico-religieux) se révèlent alors profondément ambivalentes (et éloignées des clichés habituels); on découvre qu'elles ont été significativement recomposées et transformées depuis plus d'un siècle (et parfois même en partie « inventées » sous la colonisation ou après) ${ }^{33}$, elles apparaissent comme fortement contradictoires, soumises à d'incessantes contestations, et extrêmement imbriquées dans des traits socioculturels hérités de la colonisation ou produits depuis les indépendances. Loin des généralisations culturalistes traditionalistes, c'est un enchevêtrement de micro-cultures sectorielles, d'origine et de profondeurs historiques différentes, parfois imbriquées, parfois complémentaires, parfois concurrentes, qui se donne alors à connaître ${ }^{34}$. Par exemple, ce constat fait à propos des agents de l'État en France est tout aussi valable en Afrique : «L'expérience professionnelle quotidienne est l'une des circonstances d'apprentissage culturel les plus fortes et les plus durables » (Warin 2002: 89).

Revenons à notre interrogation initiale. Pour rendre compte des comportements des agents de l'État ou des pratiques politiques contemporaines, que l'on soit politologue ou anthropologue, il est parfaitement légitime d'analyser la culture professionnelle des douaniers ou celle des magistrats, ou de décrire la culture politique électorale prévalant lors des scrutins municipaux, sans pour autant tomber dans le piège culturaliste traditionaliste. De tels usages prudents et sectorialisés du concept de culture doivent toutefois reposer nécessairement, directement ou indirectement, sur des enquêtes empiriques solides, mettant en évidence les régulations partagées de pratiques et de représentations communes spécifiques (si possible avec la médiation de concepts exploratoires tels que celui de "normes pratiques»). C'est ainsi que pourront mieux être pris en compte les diversités, les ambiguïtés, les innovations, les syncrétismes, les contradictions, les routines, les conflits, qui sont typiques des situations africaines contemporaines, et que le CTA ignore, oblitère ou sous-estime.

\section{BIBLIOGRAPHIE}

ALEXANDER, J., 1990 « Analytic Debates : Understanding the Relative Autonomy of Culture », in J. ALEXANDER \& S. SEIDMAN (eds.), Culture and Society. Contemporary Debates, Cambridge, Cambridge University Press : 1-27.

AlthaBE, G., FABRE, D. \& LenClud, D., 1992 Vers une ethnologie du présent, Paris, Éditions de la Maison des sciences de l'Homme.

AMSELLE, J.-L., 1996 « Le N’Ko au Mali », Cahiers d'Études africaines, XXXVI (4), 144 : 823-826. 
AMSELle, J.-L. \& м'вокоLо, Е. (dir.), 1985 Au cour de l'ethnie. Ethnies, tribalisme et État en Afrique, Paris, La Découverte.

BAKO ARIFARI, N., 1995 « Démocratie et "logique du terroir" au Bénin », Politique africaine, 59 : 7-24.

BARDHAN, P. \& RAY, I. (eds.), 2008 The Contested Commons : Conversations Between Economists and Anthropologists, London, Zed Books.

BASSO, K. \& SELBY, H. (eds.), 1976 Meaning Anthropology, Albuquerque, University of New Mexico Press.

BAYART, J.-F., 1996 L'illusion identitaire, Paris, Fayard.

BAZIN, J., 1985 « À chacun son Bambara », in J.-L. AMSELLE \& E. M’BoKolo (dir.), op. cit. : 87-127.

BENNETT, J., 1966 « Further Remarks on Foster's Image of Limited Good », American Anthropologist, 68 (1) : 206-209.

BLUNDO, G., 2007 « La corruption et l'État en Afrique vus par les sciences sociales. Un bilan historique », in G. BLUNDO \& J.-P. OLIVIER DE SARDAN (dir.), op. cit. : 29-78.

BLUNDO, G. \& OLIVIER DE SARDAN, J.-P. (dir.), 2007 État et corruption en Afrique. Une anthropologie comparative des relations entre fonctionnaires et usagers (Bénin, Niger, Sénégal), Paris, Karthala. BOLTANSKI, L. \& THÉVENOT, L., 1991 De la justification : les économies de la grandeur, Paris, Gallimard. BONTE, P. \& IZARD, M., 2000 [1991], Dictionnaire de l'ethnologie et de l'anthropologie, Paris, PUF. CELHTO, 2008 La charte de Kurukan Fuga. Aux sources d'une pensée politique en Afrique, Paris, L'Harmattan.

CHABAL, P. \& DALOZ, J.-P., 2006 Culture Troubles. Politics and the Interpretation of Meaning, London, Hurst \& Co.

CHABAL, P. \& DALOZ, J.-P. (eds.), 1998 Africa Works : Disorder as Political Instrument, Oxford, James Currey.

COLLECTIF, 1986 Afrique plurielle, Afrique actuelle. Hommage à Georges Balandier, Paris, Karthala (« Hommes et Sociétés »).

CONSEIL INTERNATIONAL DE LA PHILOSOPHIE ET DES SCIENCES HUMAINES, 1986 Transe, chamanisme, possession : de la fête à l'extase, Nice, Éditions Serre-Nice-Animation.

COURADE, G., 2006 L'Afrique des idées reçues, Paris, Belin.

CUCHE, D., 2004 La notion de culture dans les sciences sociales, Paris, La Découverte.

DAHOU, T., 2002 « Déculturaliser la corruption », Les Temps Modernes, 620-621 : 289-311.

DOzon, J.-P., 2003 Frères et sujets. La France et l'Afrique en perspective, Paris, Flammarion.

DOZON, J.-P. \& FASSIN, D. (dir.), 2001 Critique de la santé publique. Une approche anthropologique, Paris, Balland.

FASSIN, D., 2001 « Le culturalisme pratique de la santé publique. Critique d'un sens commun », in J.-P. DOZON \& D. FASSIN (dir.), op. cit. : 181-208.

FOSTER, G., 1965 « Peasant Society and the Image of Limited Good », American Anthropologist, 67 : 293-315., 1972 « A Second Look at Limited Good », Anthropological Quaterly, 45 (2) : 57-64.

Goodenough, W., 1971 Description and Comparison in Cultural Anthropology, Chicago, Aldine. 
GOODY, J., 1993 «Culture and its Boundaries : A European Wiew », Social Anthropology, 1 (1) : 9-32. GRIGNON, C. \& PASSERON, J.-C., 1989 Le savant et le populaire. Misérabilisme et populisme en sociologie et en littérature, Paris, Éditions du Seuil.

GRINDLE, M., 1997 « Divergent Cultures ? When Public Organizations Perform Well in Developing Countries ", World Development, 25 (4) : 481-495.

HANNERZ, U., 1992 Cultural Complexity. Studies in the Social Organization of Meaning, New York, Columbia University Press.

HARRISON, L. \& HUNTINGTON, S., 2000 Culture Matters : How Values Shape Human Progress, New York, Basic Books.

HIBOU, B. \& BANÉGAS, R., 2000 « Civil Society and the Public Space in Africa », CODESRIA Bulletin, 1 : $39-46$.

HOBSBAWN, E. \& RANGER, T., 1986 The Invention of Tradition, Cambridge, Cambridge University Press. HUtTON, C. \& RoBIN, C., 1975 « African Peasants and Resistance to Change : A Reconsideration of Sociological Approaches ", in I. OXAAL, ET AL., Beyong, the Sociology of Development : Economy and Society in Latin America and Africa, London-Boston, Routledge \& Kegan Paul : 105-130.

HYDEN, G., 2008 « Institutions, Power and Policy Outcome in Africa », Discussion Paper $\mathrm{n}^{\circ} 2$, Research program Power and Politics in Africa, (APPP), <www.institutions-africa.org>.

IZARD, M., 2000 « Culture », in P. BONTE \& M. IZARD (dir.), op. cit.

JAFFrÉ, Y., DIALLO, Y., VASSEUR, P. \& GRENIER-TORRÈs, C., 2009 La bataille des femmes. Analyse anthropologique de la mortalité maternelle dans quelques services d'obstétrique d'Afrique de l'Ouest, Descartes, Les Éditions Faustroll.

JAFFRÉ, Y. \& OLIVIER DE SARDAN, J.-P. (dir.), 2003 Une médecine inhospitalière. Les difficiles relations entre soignants et soignés dans cinq capitales d'Afrique de l'Ouest, Paris, Karthala.

JAFFRÉ, Y. \& PRUAL, A., 1993 « Le corps des sages femmes, entre identités professionnelle et sociale ", Sciences Sociales et Santé, 11 (2) : 63-80.

KABOU, A., 1991 Et si l'Afrique refusait le développement ?, Paris, L'Harmattan.

KAPLAN, D. \& SALER, B., 1966 « Foster's Image of the Limited Good : An Example of Anthropological Explanation », American Anthropologist, 68 (1) : 202-205.

KEESING, R., 1985 «Conventional Metaphor and Anthropological Metaphysics : The Problematic of Cultural Translation », Journal of Anthropological Research, 41 : 201-217.

-, 1989 « Exotic Readings of Cultural Texts », Current Anthropology, 30 (4) : 459-469.

KELSALL, T., 2008 « Going with the Grain in African Development », Development Policy Review, 26 (6) : 627-655.

KONÉ, M., 2003 « "Contexte" et "gombo" dans les formations sanitaires », in Y. JAFFRÉ \& J.-P. OLIVIER DE SARDAN (dir.), op. cit. : 237-261.

KROEBER, A. \& PARSONS, T., 1958 « The Concepts of Culture and of Social System », The American Sociological Review, 23 : 582-583.

KUPER, A., 2000 Culture. The Anthropologists' Account, Cambridge, Harvard University Press.

LAKOFF, G., 1985 Les métaphores dans la vie quotidienne, Paris, Éditions de Minuit. 
LATOUR, B., 1983 « Comment redistribuer le grand partage ? », Revue de Synthèse, 110 : 203-236.

LENCLUD, G., 1992 « Le grand partage ou la tentation ethnologique », in G. ALTHABE, D. FABRE \& G. LENCLUD (dir.), op. cit. : 9-37.

MEAGHER, K., 2006 «Cultural Primordialism and the Post-structuralist Imaginaire : plus ça change..., Africa, 76 (4) : 590-597.

MEILlassouX, C., 1975 Femmes, greniers et capitaux, Paris, Maspero.

-, 1977 Terrains et théories, Paris, Maspero.

Moumouni, A. \& SOULEY, A., 2004 « La Maternité Issaka Gazoby et l'Hôpital National de Niamey », Études et Travaux du LASDEL (Niamey) : 19-23.

OLIVIER DE SARDAN, J.-P., 1986 « Possession, exotisme, anthropologie », in Actes des $2^{\mathrm{e}}$ Rencontres internationales sur la Fête et la Communication, Nice 1985, Transe, chamanisme, possession, Nice, Éditions Serre : 149-156.

-, 1992 « Occultism and the Ethnographic "I". The Exoticizing of Magic from Durkheim to Postmodern Anthropology », Critique of Anthropology, 12 (1) : 5-25.

-, 1995 Anthropologie et développement. Essai en socio-anthropologie du changement social, Paris, Karthala.

-, 1999 « A Moral Economy of Corruption in Africa? », The Journal of Modern African Studies, 37

(1) : 25-52.

-, 2001 « La sage-femme et le douanier. Cultures professionnelles locales et culture bureaucratique privatisée en Afrique de l'Ouest », Autrepart, 20 : 61-73.

-, 2004 « État, bureaucratie et gouvernance en Afrique de l'Ouest francophone. Un diagnostic empirique, une perspective historique, Politique africaine, $96: 139-162$.

-, 2008 La rigueur du qualitatif. Les contraintes empiriques de l'interprétation socio-anthropologique, Louvain-La-Neuve, Academia-Bruylant.

ORTIGUES, E., 1991 « Culturalisme », in P. BONTE \& IZARD (dir.), op. cit. : 188-190.

OXAAL, I., BARNETT, T. \& BOOTH, D. (eds.), 1975 Beyond the Sociology of Development : Economy and Society in Latin America and Africa, London, Routledge \& Kegan Paul.

PARSONS, T. \& SCHILS, E., 1990 « Values and Social Systems », in J. ALEXANDER \& S. SEDMAN (eds.), op. cit. : $39-40$.

PASSERON, J.-C., 1991 Le raisonnement sociologique. L'espace non-poppérien du raisonnement naturel, Paris, Nathan.

Pelto, P. \& Pelto, G., 1975 « Intra-cultural Diversity : Some Theoretical Issues », American Ethnologist, 2 : 1-18.

PIAULT, H. (dir.), 1987 La colonisation : rupture ou parenthèse, Paris, L’Harmattan.

Platteau, P., 2008 « Managing the Commons : The Role of Social Norms and Beliefs ", in BARDHAN \& RAY (eds.), op. cit. : 25-45.

RANGER, T., 1986 « The Invention of Tradition in Colonial Africa », in HOBSBAWM \& RANGER (eds.), op. cit.

-, 1993 " The Invention of Tradition Revisited : the Case of Colonial Africa ", in T. RANGER \& J. VAUGHAN (eds.), Legitimacy and the State in 20th Century Africa, Oxford, The Macmillan Press. 
,- 2007 «Scotland Yard in the Bush : Medicine Murders, Child Witches and the Construction of the Occult. A Litterature Review », Africa, 77 (2) : 272-283.

RANGER, T. \& VAUGHAN, J. (eds.), 1993 Legitimacy and the State in the 20th Century Africa, Oxford, The Macmillan Press.

SANDAY, P., 1979 « The Ethnographic Paradigm(s) », Administrative Science Quaterly, 24 : 527-538.

SCHATZBERG, M. G., 1993 « Power, Legitimacy and "Democratization" in Africa », Africa, 63 :

445-461.

-, 2001 Political Legitimacy in Middle Africa : Father, Family, Food, Bloomington, Indiana University Press.

SCHNEIDER, D., 1976 « Notes Toward a Theory of Culture », in K. BASSO \& H. SELBBY (eds.), op. cit. : 197-220.

SCHUTZ, A., 1987 Le chercheur et le quotidien. Phénoménologie des sciences sociales, Paris, MéridiensKlincksieck.

scotT, J., 1990 Domination and the Arts of Resistance. Hidden Transcripts, London, Yale University Press.

-, 1998 Seeing Like a State. How Certain Schemes to Improve the Human Condition Have Failed, New Haven, Yale University Press.

SMITH, S., 2003 Négrologie : pourquoi l'Afrique meurt, Paris, Calmann-Lévy.

SOMERS, M., 1995 « What's Political or Cultural about Political Culture and the Public Sphere? Toward an Historical Sociology of Concept Formation », Sociological Theory, 13 (2) : 113-144.

SOULEY, A., 2003 « Un environnement inhospitalier », in Y. JAFFRÉ \& J.-P. OLIVIER DE SARDAN (eds.), op. cit. : 105-155.

THOMAS, K., 1971 Religion and the Decline of Magic : Studies in Popular Beliefs in Sixteenth and Seventeenth Century England, London, Weidenfeld and Nicolson.

VASSEUR, P., 2004 Socialisation des sages-femmes jeunes diplômées dans la vie active au Sénégal, Marseille, Mémoire de l'EHESS.

VEYNE, P., 1983 Les Grecs ont-ils cru à leurs mythes? Essai sur l'imagination constituante, Paris, Éditions du Seuil.

WARIN, P., 2002 Les dépanneurs de justice. Les « petits fonctionnaires » entre qualité et équité, Paris, LGDJ.

WEDEEN, L., 2007 « Conceptualizing Culture : Possibilities for Political Science », American Political Science Review, 96 (4) : 713-728.

\section{NOTES}

1. Cet article reprend diverses analyses développées lors du colloque "Culture et développement : la culture fait-elle la différence? » organisé par l'Agence française de développement (AFD) et European Development Research Network (EUDN) à Paris en décembre 2007, et lors du colloque «Socio-anthropologie et science politique face à l'espace public en Afrique : pour un dialogue productif» organisé par le Laboratoire d'études et recherches sur les dynamiques sociales et le développement local (LASDEL) à Niamey en octobre 2008. Il développe aussi quelques arguments esquissés dans un 
document de travail sur les "normes pratiques" rédigé pour le programme African Power and Politics, géré par Overseas Development Institute (texte mis en ligne sur son site <www.institutions-africa. org>). Je remercie David Booth, Philippe Lavigne Delville, Mangoné Niang et Valéry Ridde pour leurs remarques.

2. Cette charte (CELHTO 2008) a non seulement donné lieu à de nombreux débats entre historiens, mais a aussi été "réappropriée " par un mouvement politico-culturel malien, le kô (ou nko) ; sur l'idéologie du nko, voir AMSELLE (1996).

3. Par exemple, on concédera que ce fonds culturel traditionnel n'occupe quand même pas à lui tout seul le paysage, et que certaines de ses bases se transforment « Up to this point I have written about the grain of the African social fabric as though it were made up of family (largely patriarchal), religion and ethnicity and I have traced this to the pre-colonial elements. However, these are not the only significant features on the social landscape and it is possible to argue that, in some places at least, the economic foundations for these patterns are eroding " (KELSALL $2008: 648$ ).

4. Par exemple, Goran HYDEN (2008:15) considère que l'héritage de la période coloniale est purement formel : «It remained in form, not in substance. The formal rules that had been introduced by the colonial powers were largely kept intact after independence, but the value and norms that underpin a purposive bureaucracy were brushed aside. "

5. Voir OLIVIER DE SARDAN (2004) à propos du poids déterminant de l'héritage colonial sur le fonctionnement des bureaucraties africaines contemporaines.

6. On retrouve par exemple ce procédé, utilisé de façon systématique, chez des auteurs par ailleurs stimulants comme James scotT $(1990,1998)$. Le comparatisme unilatéral débridé, en quelque sorte "à la carte ", mis au service d'une théorie préexistante, est une des portes d'entrée favorites des idéologies scientifiques (populisme, culturalisme, résistocentrime, dominocentrisme, etc.).

7. Pour une critique des effets d'exotisme sur l'approche des phénomènes magicoreligieux par divers anthropologues, voir KEESING (1989) et OLIVIER DE SARDAN (1992).

8. Pour une critique des excès sur-interprétatifs de la métaphore du "manger " à propos du thème de la corruption, appuyés sur des exemples en songhay et en wolof, voir BLUNDO \& OLIVIER DE SARDAN (2007 : 137).

9. Pour une remarquable critique du durcissement des métaphores naturelles par une certaine anthropologie, voir KEESING (1985).

10. D'autres politologues français ont aussi pris leurs distances, comme Béatrice HIBOU et Richard BANÉGAS (2000: 40) dans leur critique de l'idéologie de la Banque Mondiale.

11. Nous avons été nous-mêmes, à notre grande stupéfaction, accusé de «culturalisme » (DAHOU 2002) à propos d'une tentative antérieure de dégager quelques «logiques culturelles» jouant un rôle de «facilitateur » dans la légitimation des pratiques corruptives (OLIVIER DE SARDAN 1999). Dans cet article sur l'économie morale de la corruption, nous avions pourtant pris soin d'utiliser le terme de logiques culturelles en précisant: "All these logics are syncretic, none is "traditional", none is coming directly from a so-called precolonial culture " (ibid. : 44). Le paradoxe, dans le cas du procès que nous a fait Dahou, est que sa propre interprétation de la corruption est ellemême profondément culturaliste (BLUNDO 2007 : 46-47) : il impute la banalisation de la 
corruption dans le delta du fleuve Sénégal à la logique traditionnelle de l'honneur dans le Waalo!

12. «Le culturalisme au sens large n'est pas une théorie mais une façon équivoque de raisonner sur la culture considérée comme un tout» (ORTIGUES 1991: 188-189). Inversement, la posture anti-culturaliste n'est pas non plus un paradigme et ne peut constituer un programme de recherche : elle peut tout au plus ouvrir la recherche à des questions que le culturalisme refuse de poser. Elle relève tout simplement de la vigilance envers les biais et les lieux communs, et de la méfiance face aux explications toutes faites.

13. Sur les idéologies scientifiques, qui se manifestent comme des biais méthodologiques et interprétatifs structurés et théorisés, et sur la sur-interprétation, en ses diverses figures, comme une des procédures récurrentes des idéologies scientifiques, voir OLIVIER DE SARDAN (2008).

14. J'emploie ce mot de façon symétrique à ce que Jean-Claude PASSERON (1991) appelle les « quantificateurs vagues ».

15. De façon très condensée et rapide, nous tenterons d'esquisser ici à propos de "culture " ce que Margaret SOMERS (1995) a appelé " historical sociology of concept formation" (elle-même s'y livre de façon très détaillée à propos des concepts de « political culture » chez Parsons et de « public sphere », chez Habermas).

16. Cette citation de Tylor figure aussi bien chez KUPER (2000: 56), que chez IZARD (2000 : 190) et CUCHE (2004:16).

17. Jean-Claude PASSERON $(1991$ : 323) résume ainsi ses avantages et ses inconvénients : "Le terme de "culture" n'est jamais pour l'ethnologue ou le sociologue que la nomination abstraite des devoirs d'énumération complète et d'interprétation décentrée qui incombent à la description dans les sciences sociales. Lorsque la définition ethnologique de la culture en vient à faire supposer sous ce nom l'existence d'une entité homogène capable d'opérer homogènement dans tout ce qu'elle fait faire ou ressentir à ceux qui en participent, elle revient à confondre une structure avec un capharnaüm. »

18. Le fonctionnalisme de Malinowski est un exemple de cristallisation de tels risques en théorie constituée. La théorisation de la culture comme "super-organisme " par Kroeber en est un autre exemple.

19. Parsons a eu des précurseurs, et l'on peut penser que la « personnalité de base » ou les «types culturels» (patterns of culture) de l'école dite "Culture et personnalité » avaient déjà contribué à loger la culture dans une sphère idéelle décrochée de véritable ancrage empirique, et à structurer le culturalisme en idéologie scientifique. Ruth Benedict en est même venue à d'étranges théorisations relevant du "caractère national ». L'habitus selon Pierre Bourdieu, bien que ce dernier le « loge » dans le corps (il insiste sur son "incorporation»), et qu'il ne renvoie pas à un peuple mais à une classe sociale, relève aussi selon nous de cette sphère idéelle inaccessible par l'enquête, dont l'existence est purement spéculative. Il y a une forte proximité entre la personnalité de base et l'habitus.

20. Les anthropologues postmodernes ont certes critiqué les acceptions trop globalisantes ou totalisantes du concept de culture, mais c'est en fait pour le démultiplier et le déterritorialiser, et l'appliquer aux identités collectives les plus variées (en général considérées comme dominées). 
21. Ceci a été souligné par SOMERS (1995: 117).

22. A «system of standards for perceiving, believing, evaluating and acting " (GOODENOUGH 1971 : 41, cité par SANDAY 1979 : 534).

23. Une bonne illustration en est le texte de David SCHNEIDER (1976).

24. Bien évidemment, d'un point de vue macro-historique, la distinction entre sociétés traditionnelles et sociétés modernes fait sens. C'est l'explication paresseuse des faits sociaux actuels en termes de survivances culturelles et la classification idéologique d'une partie des sociétés modernes comme étant des sociétés traditionnelles résiduelles qui posent problème.

25. Si la notion d'âme nègre est aujourd'hui totalement abandonnée, on peut penser qu'elle exprimait, dans le langage de son époque, des stéréotypes culturels peu différents des connotations qu'affectent aujourd'hui les termes plus modernes de « matrice morale » ou de « système de sens »...

26. Bien évidemment l'école de Manchester n'était pas exempte d'autres idéologies scientifiques, comme un certain fonctionnalisme, voir KUPER (2000), ou diverses formes de « holisme méthodologique ».

27. «Ce qui constitua certainement, dans ces années 1950, le tournant de la recherche africaniste française, marquant une nette rupture avec l'ethnologie coloniale, ce furent les publications très rapprochées de trois ouvrages majeurs de Georges Balandier » (DOZON 2003 : 221-222).

28. Voir, en particulier, l'influence de Claude MEILLAssoux $(1975,1977)$, lui-même ancien collaborateur de Balandier.

29. Voir, par exemple, la critique par Didier FASSIN (2001: 186) du «culturalisme pratique de la santé publique ». Pour une critique parallèle des stéréotypes culturalistes des « développeurs », voir OLIVIER DE SARDAN (1995).

30. PELto et PELTO (1975: 12), après leur critique du culturalisme uniformiste, aboutissent à une conclusion similaire : «culture » peut malgré tout rester un concept pertinent en anthropologie à condition d'être réservé à des petits groupes, des réseaux, à des individus qui ont un ensemble de ressources communes à leur disposition («cultural pool»), perspective qui laisse toute sa place aux stratégies des acteurs et à "the intra-cultural diversity".

31. Dans une telle perspective, nous avons tenté de comparer la «culture professionnelle locale» des sages-femmes et celle des douaniers (OLIVIER DE SARDAN 2001).

32. Pour un usage stimulant du concept de "culture institutionnelle ", voir GRINDLE (1997).

33. C'est le cas de nombreuses chefferies au Niger. On se rappelle les analyses de RANGER $(1986,1993)$. En un sens, l'invention et la réinterprétation profonde des traditions sont beaucoup plus «normales » et banales que leurs survivances. C'est d'autant plus vrai si l'on considère l'ampleur du «choc colonial» ou de la "rupture coloniale " (PIAULT 1987), en particulier par rapport à tout ce qui touche à l'État et à la délivrance de biens et services collectifs. Quand on est confronté en 2009 à un trait culturel précolonial avéré (ce qui est plus rare qu'on ne pourrait le penser, mais qui évidemment se produit régulièrement), c'est cette persistance surprenante qui mérite au contraire explication! 
34. Parmi les concepts exploratoires qui peuvent permettre d'appréhender cet enchevêtrement figure celui de "normes pratiques » que nous développerons ailleurs. Une culture sectorielle correspondrait alors à un ensemble spécifique de normes pratiques.

\section{RÉSUMÉS}

Résumé

Si les comportements des agents de l'État en Afrique sont si peu conformes aux normes officielles, ce serait parce qu'ils suivraient des normes sociales issues pour une bonne part de leur culture ancestrale... Cet argument n'est jamais fondé sur des analyses historiques fines, mais il est régulièrement réaffirmé, sous des habillages théoriques divers, comme par exemple en science politique avec les travaux récents de Schatzberg et de Chabal et Daloz.

Dans un premier temps, la notion de «culture africaine » est ici analysée comme un haut lieu de projection de clichés et de stéréotypes, sans ancrage empirique, qui prennent la forme d'une idéologie scientifique qu'on pourrait appeler le «culturalisme traditionaliste africaniste » (СTA), procédant par l'oubli des contre-exemples et ignorant la multiplicité des répertoires et des logiques sociales, comme la complexité et l'hétérogénéité des sociétés locales ou des mondes professionnels, et privilégiant les seules dimensions exotiques pour un regard occidental (parenté, ethnie, forces occultes). Dans un deuxième temps, c'est l'histoire même du concept de " culture » dans le champ spécifique de l'anthropologie et de la sociologie qui est examinée de façon critique. La réorganisation sémantique de ce concept par Talcott Parsons et Clifford Geertz a pavé la voie à l'idéologie culturaliste moderne, en décrochant le concept de ses ancrages empiriques antérieurs, et en l'insérant dans une dichotomie «tradition vs modernité ». Dans un troisième temps, un usage alternatif mesuré, empiriquement fondé, du concept de « culture », est proposé, aussi éloigné que possible du culturalisme : une culture est un ensemble de pratiques et de représentations dont des enquêtes auront montré qu'elles étaient significativement partagées par un groupe (ou un sous-groupe) donné, dans des domaines donnés, et dans des contextes donnés. Loin des généralisations abusives, on met alors l'accent sur les systèmes d'interactions, et les cultures locales, institutionnelles ou professionnelles, avec leur plasticité, leur syncrétisme, leur diversité, leur ambivalence.

\section{Abstract}

If African civil servants do not behave in accordance with official standards, it is because they follow social norms that mainly derive from their ancestral culture... While that argument is never based on detailed historical analysis, it is nevertheless regularly asserted in various theoretical guises, as for instance in political science in recent works by Schatzberg, Chabal and Daloz.

Here we first analyse the notion of "African culture" as the focus point for projecting clichés and stereotypes without empirical foundations that form a scientific ideology we call "Africanist traditionalist culturalism" (ATC). This conveniently forgets counter-examples and ignores the numerous social repertories and logics, such as the complexity and heterogeneity of local societies and professional communities, and only emphasizes the exotic aspects for Western viewpoints (relationships, ethnic groups, supernatural forces, etc.). Next, we carry out a critical examination of the history of the concept of "culture" in the specific fields of anthropology and 
sociology. The semantic reorganisation of this concept by Talcott Parsons and Clifford Geertz paved the way for modern culturalist ideology by detaching the concept from its former empirical roots and inserting it into a "tradition vs. modernity" dichotomy. Lastly we suggest a moderate alternative usage of the concept of "culture", which has empirical foundations and is as far removed as possible from culturalism. A culture is a set of practices and representations that surveys have shown to be significantly shared by a given group (or sub-group) in a given area and in a given context. Setting aside excessive generalizations, we emphasize systems of interaction and local, institutional or professional cultures, with their own malleability, syncretism, diversity and ambivalence.

INDEX

Mots-clés : anthropologie, culturalisme, culture, culture africaine

Keywords : Anthropology, Culturalism, Culture, African Culture

\section{AUTEUR}

\section{JEAN-PIERRE OLIVIER DE SARDAN}

Laboratoire d'études et de recherches sur les dynamiques sociales et le développement local (LASDEL), Niamey, Niger. 